\title{
Antiproteinuric Effect of Aliskiren versus Losartan in Primary Glomerulonephritis
}

\author{
Abdul Halim Abdul Gafor1, Azrini Abdul Aziz1, Rozita Mohd1, Rizna Abdul Cader1, \\ Kong Wei Yen', Shamsul Azhar Shah', Norella C. T. Kong1 \\ ${ }^{1}$ Nephrology Unit, Department of Medicine, University Kebangsaan Malaysia Medical Centre, Jalan Yaacob \\ Latif, Bandar Tun Razak, Cheras, Kuala, Lumpur, Malaysia \\ ${ }^{2}$ Department of Epidemiology and Biostatistics, University Kebangsaan Malaysia Medical Centre, Jalan Yaacob \\ Latif, Bandar Tun Razak, Cheras, Kuala, Lumpur, Malaysia \\ Email: halimgafor@gmail.com
}

Received 25 March 2014; revised 20 April 2014; accepted 14 May 2014

Copyright (C) 2014 by authors and Scientific Research Publishing Inc.

This work is licensed under the Creative Commons Attribution International License (CC BY).

http://creativecommons.org/licenses/by/4.0/

cC) (i) Open Access

\begin{abstract}
Introduction: Treatment with renin-angiotensin-aldosterone-system (RAAS) blockers plays a major role in halting chonic kidney disease (CKD) progression. Aliskiren is the first orally available direct renin inhibitor (DRI). Objective: We studied the efficacy of aliskiren compared to losartan in patients with primary GN. Design and Method: This was a prospective open-label randomized control trial in patients with primary GN. Patients were randomized to receive either aliskiren or losartan to maximum tolerated doses for 24 weeks. Blood and urine investigations were measured at baseline and at 4-weekly intervals. Adverse effects were recorded. Results: 22 patients were recruited (aliskiren-11 and losartan-11). Their baseline characteristics were comparable with the exception of a higher proteinuria (uPCI) in the aliskiren arm. There were no significant differences in proteinuria, blood pressure and other renal parameters between both groups. At end-study, only patients in the aliskiren arm showed significant reductions in both the systolic blood pressure and in proteinuria. There were no changes in the other parameters of renal function over time and no adverse events occurred. Conclusion: Aliskiren appears to be as efficacious and tolerable as losartan both as an antihypertensive and antiproteinuric agent in this study.
\end{abstract}

\section{Keywords}

Primary Glomerulonephritis, Hypertension, Proteinuria, Aliskiren, Losartan

\section{Introduction}

Glomerulonephritis (GN) either primary or secondary is clinically manifested by proteinuria, hematuria, edema 
with/without hypertension. The incidence of primary GN varies between $0.2 / 100,000 /$ year and 2.5/100,000/year [1]. The commonest primary GNin Malaysia was minimal change disease (MCN, 33.4\%), followed by focal segmental glomerulosclerosis (FSGS, 29.3\%), Immunoglobulin A nephropathy (IgAN, 19.6\%) and idiopathic membranous nephropathy (9.8\%) [2]. Chronic GN is the third leading cause of end stage renal disaese (ESRD) after diabetes mellitus and hypertension among Europeans [3], while in Malaysia it was reported that $30 \%$ of new ESRD to have underlying GN [4].

Proteinuria is an important predictor of outcome for ESRD in both diabetic nephropathy and primary GN [5][9]. The greater the proteinuria the faster the estimated glomerular filtration rate (eGFR) decline [10]. Treatment with renin-angiotensin-aldosterone-system (RAAS) blockers plays a major role in halting chonic kidney disease progression. They confer renoprotection by acting as both antihypertensive and antiproteinuric agents. It is well established that losartan has a significant antiproteinuric effect in diabetic nephropathy and this was also demonstrated in GN [11]-[15]. Notwithstanding this, a proportion of patients still progress to ESRD.

Aliskiren is the first orally available direct renin inhibitor (DRI) that acts at the initial activation step of the RAAS thereby reducing formation of angiotensin II by angiotensin converting enzymes (ACE) and ACE-independent pathways. Just like standard angiotensin-converting enzymes inhibitors (ACE-I) and angiotensin II receptor blockers (ARB), DRIs were shown to diminish renal vascular resistance and increase renal blood flow and would be expected to provide similar renoprotective benefits. The use of aliskiren as antiproteinuric agent in diabetic nephropathy as a single agent or add-on therapy to other RAAS blockers is controversial. There were limited data on antiproteinuric efficacy of aliskiren especially as single agent in patients with primary GN. Hence, the primary objective of this study was to evaluate the antiproteinuric effect of aliskiren compared to losartan in primary glomerulonephritis, the rationale for our study. Our secondary objective was to evaluate other parameters of renal function.

\section{Methodology}

\subsection{Patients and Methods}

This was a prospective open-label randomized control trial involving patients with primary GN on follow up at the Nephrology Unit, Universiti Kebangsaan Malaysia Medical Centre (UKMMC). The study approved by the University Ethics \& Research Committee (FF-419-2011) and Malaysian National Medical Research Registry (11-778-10417).

Only patients with proteinuria of $0.3 \mathrm{~g}-3.5 \mathrm{~g} /$ day and CKD stages $1-3\left(\mathrm{eGFR}>30 \mathrm{ml} / \mathrm{min} / 1.73 \mathrm{~m}^{2}\right)$ with the diagnosis of primary GN were included in this study. Patients on stable maintenance immunosuppressive therapy were included without altering the immunosuppressive drug. All patients had blood pressure of $\leq 150 / 90$ $\mathrm{mmHg}$ and serum potassium of $<5.5 \mathrm{mmol} / \mathrm{L}$ at recruitment. Patients with known renal artery stenosis or allergy to study drugs were excluded from this study. Pregnant or lactating patients and patients with childbearing potential without effective method of birth control were also excluded from this study.

\subsection{Randomization}

Patients who met the eligibility criteria were recruited. Prior to randomization patients who were on RAAS blockers underwent a 4-week washout period. Other antihypertensive medications were continued. The patients were reviewed 2-weekly during the washout period and target systolic blood pressure (SBP) $\leq 150 \mathrm{mmHg}$ and diastolic blood pressure (DBP) $\leq 90 \mathrm{mmHg}$ were maintained. Other antihypertensive medications were added and/or dose adjusted until target blood pressure was achieved. Randomization was done in blocks of four.

\subsection{Study Protocol}

At study entry, blood samples for renal, liver and lipid profiles were taken. Spot urine sample urine Protein Creatinine Index (uPCI) was also taken. The study duration was for 24 weeks. Patients were reviewed at Weeks 0 (baseline), 2 (V1), 4 (V2), 8 (V3), 12 (V4) and 24 (V5). At Weeks 4 (V2), 8 (V3), 12 (V4) and 24 (V5)-blood pressure, uPCI and blood investigations listed above were taken each visit except for the eGFR, and lipid parameters which were evaluated at the beginning (V0) and end of the study-Week 24 (V5).

Losartan and aliskiren doses were uptitrated to the maximum tolerated dose as judged by blood pressure. Losartan dosages ranged from 50 - $100 \mathrm{mg}$ daily and those for aliskiren from 150 - $300 \mathrm{mg}$ daily. Patients were 
strongly advised to adhere to the study drugs given and to report any adverse reactions either by phone or during clinic visits. Patient compliance to study treatment was assessed by pill counts. Compliance was taken as adherence with medications $\geq 80 \%$ of the time.

\subsection{Statistical Analysis}

All data were recorded and analyzed using the statistical package Statistical Package for the Social Sciences version 20 (IBM SPSS, Armonk, NY: IBM Corp). Results were expressed as median with interquartile range (IQR). The differences between two groups were analyzed using the Mann-Whitney-U test. Related data across time were analyzed using both the Wilcoxon Signed Rank test and the Friedman's test. Nominal and ordinal data were analyzed using Fisher's exact test. Nonparametric correlations were analyzed using Spearman's Rank Order Correlation. Binary logistic regression was used to analyze confounding variables. A p value of $<0.05$ was considered significant.

\section{Results}

143 patients were screened and 60 patients were noted to be in complete remission with proteinuria $<0.3 \mathrm{~g} /$ day. Twenty three patients were excluded as they were not on stable immunosuppressive therapies, 17 patients had CKD above stage 3, five declined, four females had breast cancer, six females were pregnant, two patients were HepBsAg positive and another four were planning to get pregnant. Hence, only 22 patients were recruited with 11 randomized to receive aliskiren and 11 to losartan.

Baseline demographics and clinical characteristics were tabulated in Table 1. Baseline laboratory investigations were tabulated in Table 2. The median dose of aliskiren used was 300 (150 - 300) mg daily and losartan 100 (50 - 100) mg daily. Other concurrent medicatins were no difference in between both groups.

Table 1. Baseline demographics and clinical characteristics of the study groups.

\begin{tabular}{|c|c|c|c|}
\hline Parameters & Aliskiren $(\mathrm{n}=11)$ & Losartan $(n=11)$ & $\mathrm{p}$ value \\
\hline Age (years) & $41(33-52)$ & $44(36-61)$ & 0.224 \\
\hline Male & $3(13.6 \%)$ & $8(36.4 \%)$ & 0.086 \\
\hline Female & $8(36.4 \%)$ & $3(13.6 \%)$ & \\
\hline Weight (kg) & $66.4(61.0-76.0)$ & $74.0(56.0$ - 83.0) & 0.847 \\
\hline Height (cm) & $164.0(160.0-170.0)$ & $170.0(155.0-175.0)$ & 0.973 \\
\hline Body mass index $\left(\mathrm{kg} / \mathrm{m}^{2}\right)$ & $22.24(21.40$ - 25.85) & $25.43(23.82-28.14)$ & 0.203 \\
\hline \multicolumn{4}{|l|}{ Blood pressure in $\mathrm{mmHg}$} \\
\hline Systolic BP & $133(128-140)$ & $140(130-158)$ & 0.356 \\
\hline Diastolic BP & $80(67-90)$ & $80(70-88)$ & 0.716 \\
\hline \multicolumn{4}{|l|}{ Primary Glomerulonephritis } \\
\hline Ig AN & $9(40.9 \%)$ & $7(31.8 \%)$ & 1.0 \\
\hline FSGS & $2(9.1 \%)$ & $3(13.6 \%)$ & \\
\hline Membranous & $0(0 \%)$ & $1(4.5 \%)$ & \\
\hline Age at diagnosis (years) & $32(28-40)$ & $38(28-55)$ & 0.189 \\
\hline Disease duration (years) & $5(2-7)$ & $6(3-9)$ & 0.355 \\
\hline \multicolumn{4}{|l|}{ Baseline Co-Morbidities } \\
\hline Hypertension & $4(40 \%)$ & 7 (87.5\%) & 0.066 \\
\hline Dyslipidaemia & $6(60 \%)$ & $5(62.5 \%)$ & 1.000 \\
\hline Smoking & $1(10 \%)$ & $0(0 \%)$ & 1.000 \\
\hline
\end{tabular}

Results in median (IQR), IQR: interquartile range; IgAN: IgA nephropathy; FSGS: Focal segmental glomerulosclerosis; p value $<0.05$ is significant. 
Table 2. Baseline laboratory parameters of the two study groups.

\begin{tabular}{|c|c|c|c|}
\hline Parameters & Aliskiren $(\mathrm{n}=11)$ & Losartan $(\mathrm{n}=11)$ & $\mathrm{p}$ value \\
\hline Haemoglobin (g/dl) (NR: 4.0 - 10.0) & $13.3(12.35-14.0)$ & $13.25(12.2-14.5)$ & 0.742 \\
\hline Se urea (mmol/L) (NR: 2.5 - 6.4) & $4.7(3.9-5.7)$ & $3.9(3.3-5.5)$ & 0.236 \\
\hline Se creatinine (umol/L) (NR: 62 - 106) & $85(72-108)$ & $73(66-112)$ & 0.818 \\
\hline Se potassium (mmol/l) (NR: 3.5 - 5.0) & $4.3(4.0-4.5)$ & $3.8(3.8-4.0)$ & 0.054 \\
\hline Se uric acid (umol/l) (NR: 149 - 450) & $367(306.5-401)$ & $429(292.7-507.7)$ & 0.102 \\
\hline Se albumin (g/L) (NR: 35 - 50) & $43(40-45)$ & $43(41.7-44.5)$ & 0.695 \\
\hline uPCI (g/mmol creat) (NR: <0.02) & $0.10(0.07-0.16)$ & $0.05(0.04-0.11)$ & 0.043 \\
\hline \multicolumn{4}{|l|}{ CKD } \\
\hline Stage 1 & $2(9.1 \%)$ & $4(18.2 \%)$ & 1.00 \\
\hline Stage 2 & $6(27.3 \%)$ & $5(22.7 \%)$ & \\
\hline Stage 3 & $3(13.6 \%)$ & $2(9.1 \%)$ & \\
\hline eGFR (ml/min/1.7m²) & $65(57-73)$ & $79(56-105)$ & 0.278 \\
\hline
\end{tabular}

Results in median (IQR), IQR: interquartile range; uPCI: urine protein index; CKD: Chronic Kidney Disease; eGFR: estimated glomerular filtration rate; HDL: high-density lipoprotein; LDL: low-density lipoprotein; p value $<0.05$ is significant.

The changes in uPCI were tabulated in Table 3. There were no significant changes in serum ceatinine, eGFR, serum potassium, uric acid levels and serum albumin in between both groups. The changes of blood pressure were tabulated in Table 4. Correlations between changes in uPCI and other variables such as blood pressure, serum creatinine, albumin and body mass index (BMI) were analyzed using Spearman's Rank Order Correlation. There was no significant correlation between uPCI with serum albumin, creatinine, BMI or DBP. There was significant correlation at week 12 between uPCI and SBP. However on further analysis with binary logistic regression, SBP was not a predictor for reduction in uPCI. There were no adverse effects seen during the 24 weeks study period. There was no hyperkalaemia or deterioration in renal function seen. All patients tolerated the drugs and were able to complete the 24 weeks study period.

\section{Discussion}

Many short term clinical studies in diabetic and non-diabetic chronic kidney disease (CKD) have shown that aliskiren as add-on therapy to standard a ACE-I and/or ARB reduced proteinuria by a further 20\% - 70\% [16][21]. Unfortunately the role of aliskiren in diabetic nephropathy was controversial following the results from ALTITUDE study that revealed adding Aliskiren to ACE-I of ARB caused higher adverse events which included non-fatal stroke, renal dysfunction and hyperkalaemia [22].

There were very few published studies on the antiproteinuric efficacy of aliskiren in patients with primary GN, hence the rationale for our study. In addition, ours was a head-to-head comparison of the antiproteinuric effect of aliskiren (DRI) to an ARB (losartan) in proteinuric primary GN patients.

The baseline laboratory parameters were comparable and statistically not significant with the exception of heavier proteinuria in the aliskiren arm. At the end of the study period of 24 weeks, the aliskiren group showed a significant 20\% reduction of proteinuria compared to baseline. Of these, three out of the 11 patients achieved $\geq 50 \%$ reduction of their baseline proteinuria. This result is comparable with other studies of similar duration such as AVOID (18\%) in diabetic nephropathy [23], Tang et al. (22\%) in IgA nephropathy [20] and Li et al. (26\%) in non-diabetic CKD [19]. However these studies utilized aliskiren as add-on therapy to ARB and not as single agent as in our study.

A head-to-head comparison between aliskiren and perindopril (ACEI) by Lizakowski et al. was conducted in 14 patients with non-diabetic CKD [17]. After 12 weeks of either aliskiren or perindopril the patients were crossed over to the other arm for another 12 weeks of treatment after a 12 -week washout period. The authors reported that treatment with aliskiren $300 \mathrm{mg}$ /day reduced 24-h proteinuria by 36\% compared to placebo. This 
Table 3. Changes of uPCI with time for both study groups.

\begin{tabular}{|c|c|c|c|c|c|c|c|}
\hline & & Week 0 & Week 4 & Week 8 & Week 12 & Week 24 & $\begin{array}{l}\text { p value } \\
\text { (intragp) }\end{array}$ \\
\hline \multirow{2}{*}{ uPCI (g/mmol) } & Aliskiren & $\begin{array}{c}0.10 \\
(0.07-0.16)\end{array}$ & $\begin{array}{c}0.065 \\
(0.03-0.12)\end{array}$ & $\begin{array}{c}0.07 \\
(0.03-0.12)\end{array}$ & $\begin{array}{c}0.07 \\
(0.03-0.11)\end{array}$ & $\begin{array}{c}0.08 \\
(0.03-0.12)\end{array}$ & 0.033 \\
\hline & Losartan & $\begin{array}{c}0.05 \\
(0.04-0.11)\end{array}$ & $\begin{array}{c}0.05 \\
(0.02-0.08)\end{array}$ & $\begin{array}{c}0.05 \\
(0.02-0.11)\end{array}$ & $\begin{array}{c}0.04 \\
(0.02-0.13)\end{array}$ & $\begin{array}{c}0.03 \\
(0.02-0.10)\end{array}$ & 0.736 \\
\hline p value (Intergp) & & 0.043 & 0.501 & 0.263 & 0.290 & 0.319 & \\
\hline
\end{tabular}

Data expressed in median (IQR), IQR = interquartile range; $\mathrm{p}<0.05$ is significant. Intragroup: Using Friedman's two-way analysis; Intergroup: Using Mann-Whitney-U.

Table 4. Changes of blood pressure with time in both study groups.

\begin{tabular}{|c|c|c|c|c|c|c|c|}
\hline $\mathrm{BP}$ & & Week 0 & Week 4 & Week 8 & Week 12 & Week 24 & $\begin{array}{l}\mathrm{p} \text { value } \\
\text { (intra-gp) }\end{array}$ \\
\hline \multirow{3}{*}{ Systolic BP } & Aliskiren & $\begin{array}{c}133 \\
(128-140)\end{array}$ & $\begin{array}{c}129 \\
(118-133)\end{array}$ & $\begin{array}{c}124 \\
(116-130)\end{array}$ & $\begin{array}{c}121 \\
(117-132)\end{array}$ & $\begin{array}{c}123 \\
(114-136)\end{array}$ & 0.013 \\
\hline & Losartan & $\begin{array}{c}140 \\
(130-158)\end{array}$ & $\begin{array}{c}128 \\
(123-140)\end{array}$ & $\begin{array}{c}130 \\
(120-139)\end{array}$ & $\begin{array}{c}130 \\
(122-140)\end{array}$ & $\begin{array}{c}130 \\
(117-140)\end{array}$ & \multirow[t]{2}{*}{0.432} \\
\hline & $\begin{array}{c}\mathrm{p} \text { value } \\
\text { (inter-gp) }\end{array}$ & 0.323 & 0.793 & 0.222 & 0.114 & 0.264 & \\
\hline \multirow{3}{*}{ Diastolic BP } & Aliskiren & $\begin{array}{c}80 \\
(67-90)\end{array}$ & $\begin{array}{c}75 \\
(66-86)\end{array}$ & $\begin{array}{c}75 \\
(65-80)\end{array}$ & $\begin{array}{c}75 \\
(66-81)\end{array}$ & $\begin{array}{c}71 \\
(62-83)\end{array}$ & 0.313 \\
\hline & Losartan & $\begin{array}{c}80 \\
(70-88)\end{array}$ & $\begin{array}{c}70 \\
(68-86)\end{array}$ & $\begin{array}{c}75 \\
(70-88)\end{array}$ & $\begin{array}{c}80 \\
(70-90)\end{array}$ & $\begin{array}{c}74 \\
(70-80)\end{array}$ & \multirow[t]{2}{*}{0.418} \\
\hline & $\begin{array}{c}\mathrm{p} \text { value } \\
\text { (inter-gp) }\end{array}$ & 0.716 & 0.817 & 0.428 & 0.197 & 0.448 & \\
\hline
\end{tabular}

Data expressed in median (IQR), IQR = interquartile range; $\mathrm{p}<0.05$ is significant Intragroup: Using Friedman's two-way analysis; Intergroup: Using Mann-Whitney-U.

was not different when compared with perindopril $10 \mathrm{mg} /$ day which decreased proteinuria by $25 \%$.

Persson et al. are the only other investigators who have conducted a head-to-head comparison between aliskiren monotherapy, irbesartan (ARB) monotherapy or combined aliskiren-irbesartan to placebo in Type 2 diabetic patients with nephropathy [16]. In this studyaliskiren was as effective as irbesartan compared with placebo and reduced proteinuria by $48 \%$ and $58 \%$ respectively. The combination showed significant proteinuria reduction compared to either monotherapy as expected.

Thus, to our best knowledge, our study was the first head-to-head comparison of the antiproteinuric effect between a direct renin inhibitor and ARB in patients with primary GN.

A subanalysis of the study by Persson et al. reports that the optimal antiproteinuric dose for aliskiren is 300 mg daily with $48 \%$ reduction compared to placebo [24]. Studies by Parving et al. (AVOID) [23], Gupta et al. [25] and Lizakowski et al. [17] also titrated aliskiren dose to $300 \mathrm{mg}$ daily. The median dose used for aliskiren in our study was $300 \mathrm{mg}$ daily.

Multicentre trials have shown that the optimal antiproteinuric dose for losartan is $100 \mathrm{mg}$ daily and that no additional benefit was seen beyond this dose [26]. However, other studies have also shown that losartan even at doses as low as $25 \mathrm{mg}$ daily significantly reduces proteinuria as hypertension is not always present in cases of early non-diabetic CKD [12]. In our study, there was also "mild" proteinuria reduction in the losartan group at end study but this did not achieve significance [median $0.05(0.04-0.11) \mathrm{g} / \mathrm{mmol}$ at baseline reducing to [0.03 $(0.02-0.10)$ at end study; $p=0.736]$. One reason for this is the small number of study patients. Another reason may be due to the even lower proteinuria in this group than that in the aliskiren group. Many studies have demonstrated that the degree of proteinuria reduction was proportional to baseline proteinuria-the higher the baseline proteinuria the greater the reduction [27]-[29]. Thus the negative finding in losartan group may be due to the small number of patients and low baseline proteinuria. 
Although there were no differences in blood pressure between the two groups, aliskiren seems to be a more potent antihypertensive agent than losartan and the aliskiren group had a significantly lower systolic blood pressure. The efficacy of aliskiren as an antihypertensive has been reported in various clinical trials whether used as monotherapy or combination. Its antihypertensive effect has also been compared with various ARBs. These include valsartan, irbesartan and losartan. Aliskiren used in combination with valsartan provides significant additive and tolerable antihypertensive properties [30]. In another study, the antihypertensive efficacy of aliskiren $150 \mathrm{mg}$ was found to be similar to irbesartan $150 \mathrm{mg}$ daily [31]. Yet another study showed comparable antihypertensive effect between aliskiren $300 \mathrm{mg}$ daily and losartan $100 \mathrm{mg}$ daily [32].

In our study the antiproteinuric effect was independent of blood pressure control as patients' blood pressures were already near to target. Analysis using binary logistic regression showed that the reduction in proteinuria was independent of blood pressure or other variable. This is in agreement with that reported by many large studies where equivalent reductions in blood pressure could not account for the degree of proteinuria reduction or stability of renal function which led the authors to conclude that RAAS conferred renoprotection "beyond blood pressure reduction” [27] [33].

Aliskiren in a head-to-head comparison with losartan did not have any adverse effect on other renal function parameters. It was well tolerated and none of our patients developed any side effects. This concurs with previous studies that reported no adverse effects on renal function with aliskiren usage [17] [34].

\section{Conclusion}

Despite the small sample size, our study showed aliskiren to have comparable antiproteinuric and antihypertensive effects to ARB without any adverse effect on renal function which is well tolerated. Therefore it may be recommended that patients with primary GN who are intolerant to ACEIs or ARBs or have hypertension can be started on aliskiren. A large trial is indicated to confirm these preliminary findings.

\section{Acknowledgements}

We would like to thank the Dean of the Faculty of Medicine, Universiti Kebangsaan Malaysia, for allowing us to publish these data.

\section{Conflict of Interest}

None declared.

\section{References}

[1] McGrogan, A., Franssen, C.F. and de Vries, C.S. (2011) The Incidence of Primary Glomerulonephritis Worldwide: A Systematic Review of the Literature. Nephrology Dialysis Transplantation, 26, 414-430. http://dx.doi.org/10.1093/ndt/gfq665

[2] Sunita Bavanandan, L.S.K. (2009) 3rd Report on the Malaysian Registry of Renal Biopsy on Primary Glomerulonephritis.

[3] Couchoud, C., Stengel, B., Landais, P., Aldigier, J.C., de Cornelissen, F., Dabot, C., et al. (2006) The Renal Epidemiology and Information Network (REIN): A New Registry for End-Stage Renal Disease in France. Nephrology Dialysis Transplantation, 21, 411-418. http://dx.doi.org/10.1093/ndt/gfi198

[4] Hooi, L.S., Wong, H.S. and Morad, Z. (2005) Prevention of Renal Failure: The Malaysian Experience. Kidney International Supplements, 94, S70-S74. http://dx.doi.org/10.1111/j.1523-1755.2005.09418.x

[5] Philibert, D. and Cattran, D. (2008) Remission of Proteinuria in Primary Glomerulonephritis: We Know the Goal but Do We Know the Price? Nature Clinical Practice Nephrology, 4, 550-559. http://dx.doi.org/10.1038/ncpneph0915

[6] Hsu, C.Y., Iribarren, C., McCulloch, C.E., Darbinian, J. and Go, A.S. (2009) Risk Factors for End-Stage Renal Disease: 25-Year Follow-Up. Archives of Internal Medicine, 169, 342-350. http://dx.doi.org/10.1001/archinternmed.2008.605

[7] Astor, B.C., Matsushita, K., Gansevoort, R.T., van der Velde, M., Woodward, M., Levey, A.S., et al. (2011) Lower Estimated Glomerular Filtration Rate and Higher Albuminuria Are Associated with Mortality and End-Stage Renal Disease. A Collaborative Meta-Analysis of Kidney Disease Population Cohorts. Kidney International, 79, 1331-1340. http://dx.doi.org/10.1038/ki.2010.550

[8] Ruggenenti, P., Perna, A., Mosconi, L., Pisoni, R. and Remuzzi, G. (1998) Urinary Protein Excretion Rate Is the Best 
Independent Predictor of ESRF in Non-Diabetic Proteinuric Chronic Nephropathies. "Gruppo Italiano di Studi Epidemiologici in Nefrologia” (GISEN). Kidney International, 53, 1209-1216.

http://dx.doi.org/10.1046/j.1523-1755.1998.00874.X

[9] Iseki, K., Ikemiya, Y., Iseki, C. and Takishita, S. (2003) Proteinuria and the Risk of Developing End-Stage Renal Disease. Kidney International, 63, 1468-1474. http://dx.doi.org/10.1046/j.1523-1755.2003.00868.x

[10] Keane, W.F. (2000) Proteinuria: Its Clinical Importance and Role in Progressive Renal Disease. American Journal of Kidney Diseases, 35, S97-S105. http://dx.doi.org/10.1016/S0272-6386(00)70237-X

[11] Rutkowski, P., Tylicki, L., Renke, M., Korejwo, G., Zdrojewski, Z. and Rutkowski, B. (2004) Low-Dose Dual Blockade of the Renin-Angiotensin System in Patients with Primary Glomerulonephritis. American Journal of Kidney Diseases, 43, 260-268. http://dx.doi.org/10.1053/j.ajkd.2003.10.032

[12] Renke, M., Tylicki, L., Rutkowski, P. and Rutkowski, B. (2004) Low-Dose Angiotensin II Receptor Antagonists and Angiotensin II-Converting Enzyme Inhibitors Alone or in Combination for Treatment of Primary Glomerulonephritis. Scandinavian Journal of Urology and Nephrology, 38, 427-433. http://dx.doi.org/10.1080/00365590410015687

[13] Praga, M., Andrade, C.F., Luno, J., Arias, M., Poveda, R., Mora, J., et al. (2003) Antiproteinuric Efficacy of Losartan in Comparison with Amlodipine in Non-Diabetic Proteinuric Renal Diseases: A Double-Blind, Randomized Clinical Trial. Nephrology Dialysis Transplantation, 18, 1806-1813. http://dx.doi.org/10.1093/ndt/gfg284

[14] Tylicki, L., Rutkowski, P., Renke, M. and Rutkowski, B. (2002) Renoprotective Effect of Small Doses of Losartan and Enalapril in Patients with Primary Glomerulonephritis. Short-Term Observation. American Journal of Nephrology, 22, 356-362. http://dx.doi.org/10.1159/000065227

[15] Tylicki, L., Renke, M., Rutkowski, P., Rutkowski, B. and Lysiak-Szydlowska, W. (2005) Randomized, Controlled Study of the Effects of Losartan versus Enalapril in Small Doses on Proteinuria and Tubular Injury in Primary Glomerulonephritis. Medical Science Monitor, 11, PI31-PI37.

[16] Persson, F., Rossing, P., Reinhard, H., Juhl, T., Stehouwer, C.D., Schalkwijk, C., et al. (2009) Renal Effects of Aliskiren Compared with and in Combination with Irbesartan in Patients with Type 2 Diabetes, Hypertension, and Albuminuria. Diabetes Care, 32, 1873-1879. http://dx.doi.org/10.2337/dc09-0168

[17] Lizakowski, S., Tylicki, L., Renke, M., Rutkowski, P., Heleniak, Z., Slawinska-Morawska, M., et al. (2012) Effect of Aliskiren on Proteinuria in Non-Diabetic Chronic Kidney Disease: A Double-Blind, Crossover, Randomised, Controlled Trial. International Urology and Nephrology, 44, 1763-1770. http://dx.doi.org/10.1007/s11255-011-0110-z

[18] Moriyama, T., Tsuruta, Y., Kojima, C., Itabashi, M., Sugiura, H., Takei, T., et al. (2012) Beneficial Effect of Aliskiren Combined with Olmesartan in Reducing Urinary Protein Excretion in Patients with Chronic Kidney Disease. International Urology and Nephrology, 44, 841-845. http://dx.doi.org/10.1007/s11255-011-9991-0

[19] Li, S.Y., Chen, Y.T., Yang, W.C., Tarng, D.C., Lin, C.C., Yang, C.Y., et al. (2012) Effect of Add-On Direct Renin Inhibitor Aliskiren in Patients with Non-Diabetes Related Chronic Kidney Disease. BMC Nephrology, 13, 89. http://dx.doi.org/10.1186/1471-2369-13-89

[20] Tang, S.C., Lin, M., Tam, S., Au, W.S., Ma, M.K., Yap, D.Y., et al. (2012) Aliskiren Combined with Losartan in Immunoglobulin A Nephropathy: An Open-Labeled Pilot Study. Nephrology Dialysis Transplantation, 27, 613-618. http://dx.doi.org/10.1093/ndt/gfr349

[21] Persson, F., Rossing, P., Schjoedt, K.J., Juhl, T., Tarnow, L., Stehouwer, C.D., et al. (2008) Time Course of the Antiproteinuric and Antihypertensive Effects of Direct Renin Inhibition in Type 2 Diabetes. Kidney International, 73, 1419-1425. http://dx.doi.org/10.1038/ki.2008.68

[22] Parving, H.H., Brenner, B.M., McMurray, J.J., de Zeeuw, D., Haffner, S.M., Solomon, S.D., et al. (2012) Cardiorenal End Points in a Trial of Aliskiren for Type 2 Diabetes. The New England Journal of Medicine, 367, 2204-2213. http://dx.doi.org/10.1056/NEJMoa1208799

[23] Parving, H.H., Persson, F., Lewis, J.B., Lewis, E.J. and Hollenberg, N.K. (2008) Aliskiren Combined with Losartan in Type 2 Diabetes and Nephropathy. The New England Journal of Medicine, 358, 2433-2446. http://dx.doi.org/10.1056/NEJMoa0708379

[24] Persson, F., Rossing, P., Reinhard, H., Juhl, T., Stehouwer, C.D., Schalkwijk, C., et al. (2010) Optimal Antiproteinuric Dose of Aliskiren in Type 2 Diabetes Mellitus: A Randomised Crossover Trial. Diabetologia, 53, 1576-1580. http://dx.doi.org/10.1007/s00125-010-1789-6

[25] Gupta, A., Khaira, A., Singh, B., Bhowmik, D.M. and Tiwari, S.C. (2009) Aliskiren as an Antiproteinuric Add-On Therapy in Primary Membranous Nephropathy. Clinical and Experimental Nephrology, 13, 402-403. http://dx.doi.org/10.1007/s10157-009-0130-5

[26] Laverman, G.D., Henning, R.H., de Jong, P.E., Navis, G. and de Zeeuw, D. (2001) Optimal Antiproteinuric Dose of Losartan in Nondiabetic Patients with Nephrotic Range Proteinuria. American Journal of Kidney Diseases, 38, 13811384. http://dx.doi.org/10.1053/ajkd.2001.29262 
[27] Peterson, J.C., Adler, S., Burkart, J.M., Greene, T., Hebert, L.A., Hunsicker, L.G., et al. (1995) Blood Pressure Control, Proteinuria, and the Progression of Renal Disease. The Modification of Diet in Renal Disease Study. Annals of Internal Medicine, 123, 754-762. http://dx.doi.org/10.7326/0003-4819-123-10-199511150-00003

[28] Foundation, N.K. (2012) KDOQI Clinical Practice Guidelines for Diabetes and Chronic Kidney Disease: 2012 Updates American Journal of Kidney Diseases, 60, 850-886.

[29] Reich, H.N., Troyanov, S., Scholey, J.W. and Cattran, D.C. (2007) Remission of Proteinuria Improves Prognosis in IgA Nephropathy. Journal of the American Society of Nephrology, 18, 3177-3183. http://dx.doi.org/10.1681/ASN.2007050526

[30] Oparil, S., Yarows, S.A., Patel, S., Fang, H., Zhang, J. and Satlin, A. (2007) Efficacy and Safety of Combined Use of Aliskiren and Valsartan in Patients with Hypertension: A Randomised, Double-Blind Trial. Lancet, 370, $221-229$. http://dx.doi.org/10.1016/S0140-6736(07)61124-6

[31] Gradman, A.H., Schmieder, R.E., Lins, R.L., Nussberger, J., Chiang, Y. and Bedigian, M.P. (2005) Aliskiren, a Novel Orally Effective Renin Inhibitor, Provides Dose-Dependent Antihypertensive Efficacy and Placebo-Like Tolerability in Hypertensive Patients. Circulation, 111, 1012-1018. http://dx.doi.org/10.1161/01.CIR.0000156466.02908.ED

[32] Solomon, S.D., Appelbaum, E., Manning, W.J., Verma, A., Berglund, T., Lukashevich, V., et al. (2009) Effect of the Direct Renin Inhibitor Aliskiren, the Angiotensin Receptor Blocker Losartan, or Both on Left Ventricular Mass in Patients with Hypertension and Left Ventricular Hypertrophy. Circulation, 119, 530-537. http://dx.doi.org/10.1161/CIRCULATIONAHA.108.826214

[33] Hellemons, M.E., Persson, F., Bakker, S.J., Rossing, P., Parving, H.H., De Zeeuw, D., et al. (2011) Initial Angiotensin Receptor Blockade-Induced Decrease in Albuminuria Is Associated with Long-Term Renal Outcome in Type 2 Diabetic Patients with Microalbuminuria: A Post Hoc Analysis of the IRMA-2 Trial. Diabetes Care, 34, 2078-2083. http://dx.doi.org/10.2337/dc11-0324

[34] Ito, S., Nakura, N., Le Breton, S. and Keefe, D. (2010) Efficacy and Safety of Aliskiren in Japanese Hypertensive Patients with Renal Dysfunction. Hypertens Research, 33, 62-66. http://dx.doi.org/10.1038/hr.2009.175 